\title{
Environmental hazard of loparite ore dressing tailings
}

\author{
$E A$ Krasavtseva $^{1,2, *}, V V$ Maksimova $^{1,2}$, and $D V$ Makarov $^{2}$ \\ ${ }^{1}$ Laboratory of Nature-Inspired Technologies and Environmental Safety of the Arctic of the Federal Research Centre «Kola Science \\ Centre of the Russian Academy of Sciences», Fersmana 14, 184209 Apatity, Russia \\ ${ }^{2}$ Institute of North Industrial Ecology Problems of the Federal Research Centre «Kola Science Centre of the Russian Academy of \\ Sciences», Fersmana 14a, 184209 Apatity, Russia
}

\begin{abstract}
Mobilization of environmentally hazardous elements from loparite ore tailings when exposed to various leaching agents was studied in laboratory conditions. Leaching of pollutants from fresh tailings when exposed to atmospheric precipitation and the processes of interaction of mature tailings dust particles $(-0.071 \mathrm{~mm})$ with soil water were examined. It was found that in both cases, there is an intensive decomposition of the minerals making up the tailings and conversion of heavy metals ( $\mathrm{Zn}, \mathrm{Mn}, \mathrm{Sr}$ ) and rare earth elements of the light group ( $\mathrm{La}-\mathrm{Sm}$ ) into a dissolved, and therefore bioavailable form. At the same time, the pollutant concentrations were many times higher than the maximum permissible concentrations for fishery water bodies. The results of the experiments indicate the environmental hazard associated with loparite ore concentration tailings due to the pollution of environment with heavy metals and rare earth elements released when the tailings interact with rainwater and soil water.
\end{abstract}

\section{Introduction}

Various aspects of the negative environmental impact of the mining industry's waste in the Arctic are widely studied presently [1 - 3]. The Arctic is a global region highly vulnerable to environmental pollution. Murmansk Region is one of the most industrially developed and urbanized regions of the Russian Arctic. The mining industry, encompassing the extraction and processing of minerals, forms the core of the economic activity in the region.

Storage of tailings, overburden and tunneling rock leads to a whole range of long-term consequences for natural environments. Tailings storage facilities are locations where the tailings continuously chemically interact with atmospheric and percolating circulating ground water, which leads to the migration of pollutants into the environment. Ore crushing and grinding prior to concentration and, as a consequence, the presence of a fine fraction in the tailings results in a whole range of specific consequences $[4,5]$.

During storage, the ground material of the concentration tailings undergoes a wide range of hypergene transformations due to interaction with the atmosphere, rainwater, and soil solutions. In industrially developed regions, emissions from anthropogenic sources of atmospheric pollution with acid anhydrides, in particular $\mathrm{SO}_{2}, \mathrm{SO}_{3}, \mathrm{NO}, \mathrm{NO}_{2}$, prevail over natural emissions [6]. When dissolved in rainwater, these form acid rain, which is one of the most severe forms of environmental pollution $[7,8]$.

Previously, we studied samples of mature and fresh loparite ore concentration tailings from both fields and examined their effect on the growth and development of higher plants $[9,10]$. However, in the course of geoecological assessment of the risk of the negative impact of mining and ore processing waste on the environment, it is important to take into account acid rain as an anthropogenic environmental hazard [11].

One of the main pathways for the entry of pollutants into the environment is aeolian mass transport from tailings storage facilities. When fine dust is deposited on the soil surface or when the tailings storage facility surface gets overgrown with vegetation, the dust interacts with soil solutions. Soil organic substances are involved in physical, chemical, and biological processes, complexation, ionic, molecular, and redox reactions, and affect the transport of metals in water and soil systems $[12,13]$. Humic and fulvic acids can both strengthen the migration ability of elements and contribute to the accumulation thereof in the soil due to the formation of poorly soluble compounds. Organic substances can have a particularly strong effect on the migration ability of ecotoxicants in multicomponent rare metal tailings due to the formation of organocomplexes with metals [13].

The goal of this study is to examine the mobilization of environmentally hazardous elements from loparite ore tailings under model conditions simulating acid rain and the consequences of dust particle deposition into the soil.

\section{Materials and methdos}

The only active deposit of loparite ores is located in the center of the Kola Peninsula (Fig. 1).

\footnotetext{
* Corresponding author: vandeleur2012@yandex.ru
} 


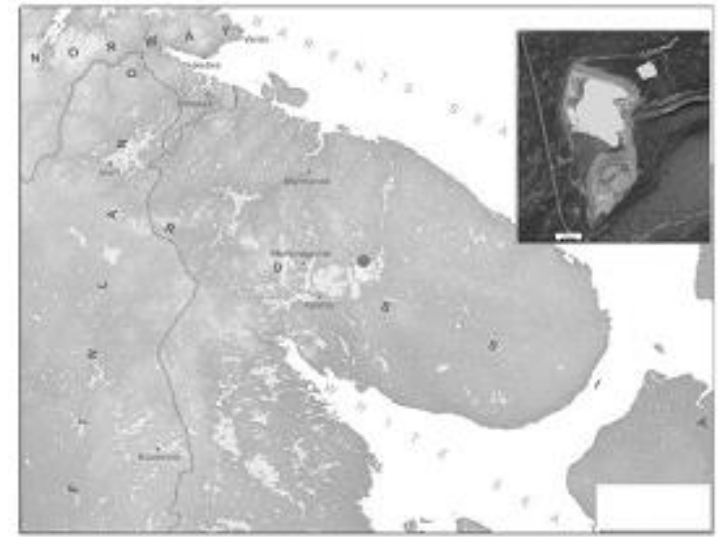

Fig. 1. Location map of the study area.

We studied fresh concentration tailings of loparite ore and dust particles (size fraction $-0.071 \mathrm{~mm}$ ) of mature tailings. The main minerals making up the tailings are nepheline, feldspars, aegirine. Impurities of sodalite, apatite, loparite were found. The content of some elements in the loparite ore concentration tailings is shown in Table 1.

Table 1. Content of elements in the loparite ore concentration tailings, $\mathrm{mg} / \mathrm{kg}$.

\begin{tabular}{|c|c|c|}
\hline Element & Current tails & Mature tails (-0.071 mm) \\
\hline $\mathrm{Cu}$ & 6.44 & 13.3 \\
\hline $\mathrm{Sr}$ & 1289 & 1265 \\
\hline $\mathrm{Zn}$ & 240 & 321 \\
\hline $\mathrm{La}$ & 202 & 266 \\
\hline $\mathrm{Ce}$ & 1031 & 1771 \\
\hline $\mathrm{Pr}$ & 38.8 & 44.5 \\
\hline $\mathrm{Nd}$ & 121 & 151 \\
\hline $\mathrm{Mn}$ & 1580.84 & 1956.13 \\
\hline $\mathrm{Al}$ & 75762.28 & 68131.29 \\
\hline
\end{tabular}

Modeling of chemical weathering of minerals when exposed to atmospheric precipitation was carried out according to the previously described method by examining the interaction of the particles of fresh loparite ore concentration tailings with distilled water and a weak solution of sulfuric acid [11]. Considering the time span of the natural hypergene processes in minerals, the experiment was carried out in accelerated conditions. Samples of loparite ore concentration tailings $(m=70 \mathrm{~g})$ were placed in temperature-controlled cells $(t$ $=50{ }^{\circ} \mathrm{C}$ ). The samples were moistened daily with 0.002 $\mathrm{N}$ sulfuric acid solution at a rate of $25 \mathrm{ml}$ daily for 20 , 40 , and 60 days. In the control series of experiments, distilled water acted as a leaching agent. At the end of the experiment, the dried samples were treated with distilled water at a $\mathrm{S}: \mathrm{L}$ ratio of 1:10.

The interaction of the dusty fraction of mature tailings with model solutions simulating soil waters was also studied in laboratory conditions. A water extract of soil sampled at a distance of $20 \mathrm{~km}$ from the industrial site was used as a model solution. The extract was prepared in accordance with GOST 26423-85 [14]. Organic carbon content in the extracts was approximately $40 \mathrm{mg} / \mathrm{l}$, which is comparable with the average $\mathrm{C}_{\text {org }}$ value in the podzolic soils of the Kola
Peninsula as reported in the literature [15]. Weighed charges of the loparite ore concentration tailings (fraction size $-0.071 \mathrm{~mm}$ ) were added to the resulting solutions at a S:L ratio of 1:10. As a control, a series of similar experiments using distilled water was carried out. The reaction time was $1,3,5$ hours with continuous stirring.

The resulting solutions were filtered using a Vladipore membrane filter MFAS-OS-2 (pore size 0.47 $\mu \mathrm{m})$ and sent for quantitative chemical analysis to the Shared Use Center, Institute of Industrial Ecology of the North, Kola Research Center at the Russian Academy of Sciences.

\section{Results and discussion}

\subsection{Mobilization of environmentally hazardous elements from loparite ore concentration tailings when exposed to atmospheric precipitation}

The objective was to trace the hypergene changes in nepheline and other silicates, which are the main minerals in the loparite ore concentration tailings. Silicate matrix breakup under the action of distilled water and dilute sulfuric acid was assessed by analyzing the filtrates for aluminum, silicon, sodium, and potassium (Fig. 2).

In the experiments using dilute sulfuric acid, the dissolution of minerals and the release of these elements increased significantly. It should be noted that while it is silicon that predominantly passes into the solution when interacting with water, when the tailings are moistened with a solution of sulfuric acid, alumina-oxygen tetrahedra are destroyed more intensively with the formation of $\mathrm{Al}_{2}\left(\mathrm{SO}_{4}\right)_{3}$.

After the interaction of the tailings with distilled water, the concentrations of potassium and sodium increase, especially intensively in the time interval 40 to 60 days. The dissolution of minerals occurs incongruently, with the predominant release of sodium ions: its concentration exceeds that of potassium by a factor of nearly 20 at the end of the experiment. When the loparite ore concentration tailings interact with dilute sulfuric acid, the dissolution of nepheline proceeds much more intensively, while maintaining the uneven transition of elements into solution.

The change in the concentration in the resulting solutions of some heavy metals (HMs) and rare earth elements (REEs) in the loparite ore concentration tailings depending on the duration of the experiment and the leaching agent added is shown in Fig. 3. It can be seen that when the tailings particles interacted with distilled water, the fishery MPC for manganese $(10 \mu \mathrm{g} / \mathrm{l})$ was slightly exceeded already on the first day. During the experiment, the concentration of strontium practically did not change, while that of zinc increased slightly.

When the loparite ore concentration tailings interacted with sulfuric acid solution, the transition of HMs into solution increased sharply. Moreover, their 
Al

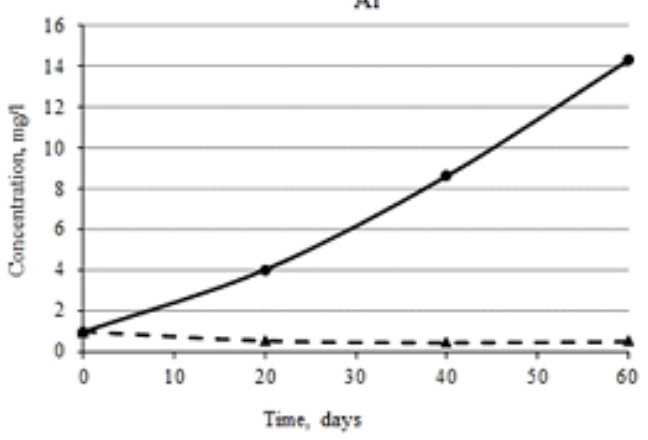

$\mathrm{Na}$

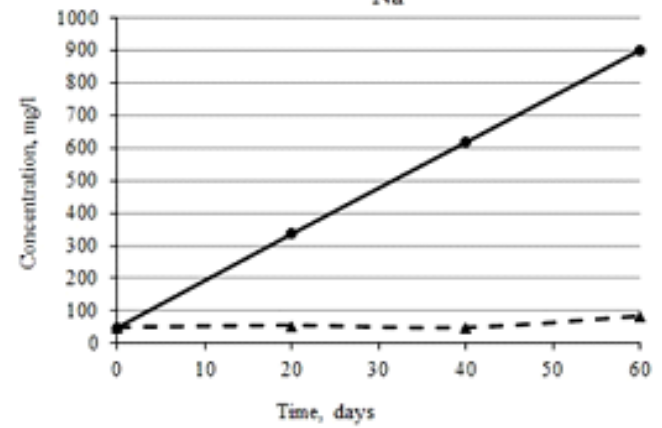

$\mathrm{Si}$

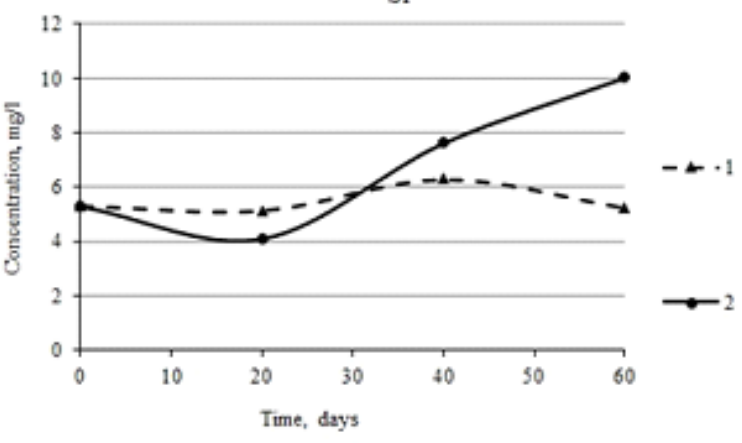

$\mathrm{K}$

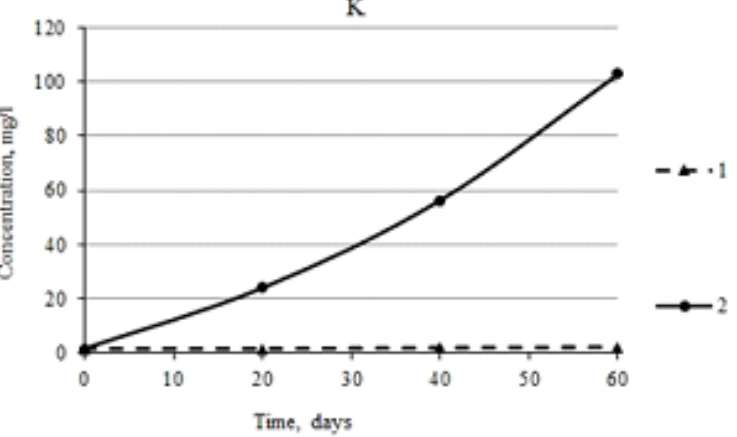

Fig. 2. Concentrations of aluminum, silicon, sodium, and potassium in the resulting solutions when interacting with water (1) and sulfuric acid (2).

concentrations are more than an order of magnitude higher than those in the experiment with distilled water in the first twenty days of the experiment. After 60 days, the exceedance of the fishery MPC becomes larger: strontium exceeds the maximum permissible concentration by a factor of 5 , zinc 17, manganese 448 .

The transition of REEs into solution is also intensified when sulfuric acid solution is added as a leaching agent instead of distilled water. In particular, the concentration of lanthanum and cerium in the resulting solutions at the end of the experiment exceeds the corresponding values in the control (moistening with distilled water) by a factor of 45 and 60 , respectively.

Thus, the interaction between the concentration

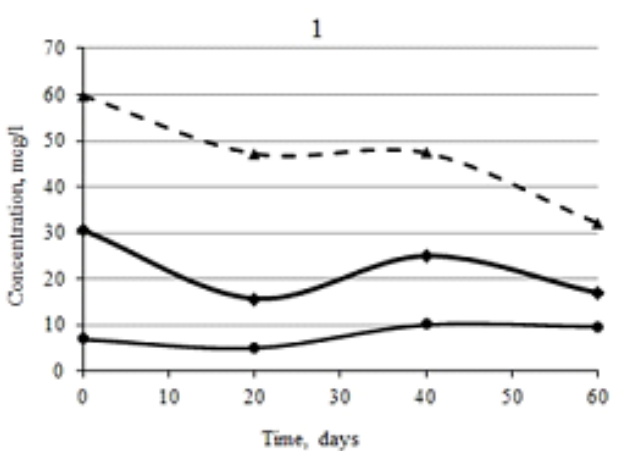

1

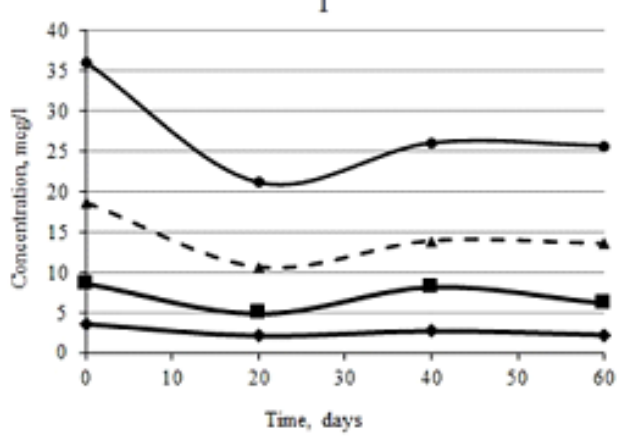

$\mathrm{HM}$

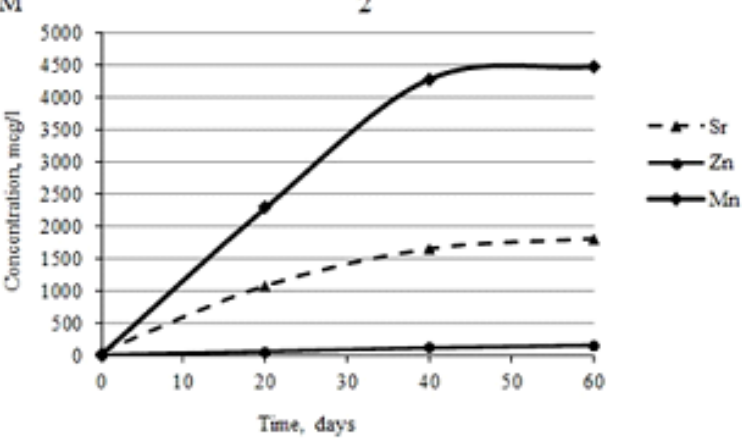

REE

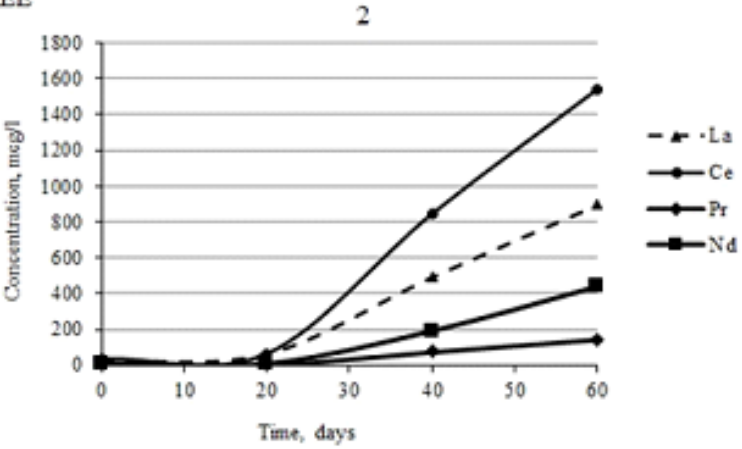

Fig. 3. Concentrations of HMs and REEs in the resulting solutions when interacting with water (1) and sulfuric acid (2). 
Al

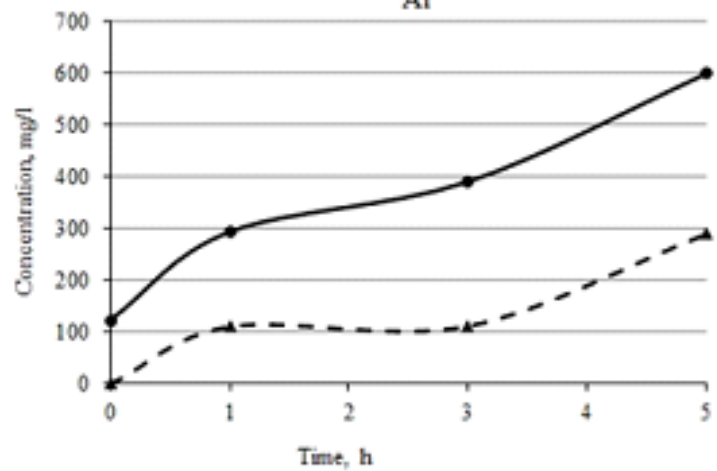

$\mathrm{Na}$

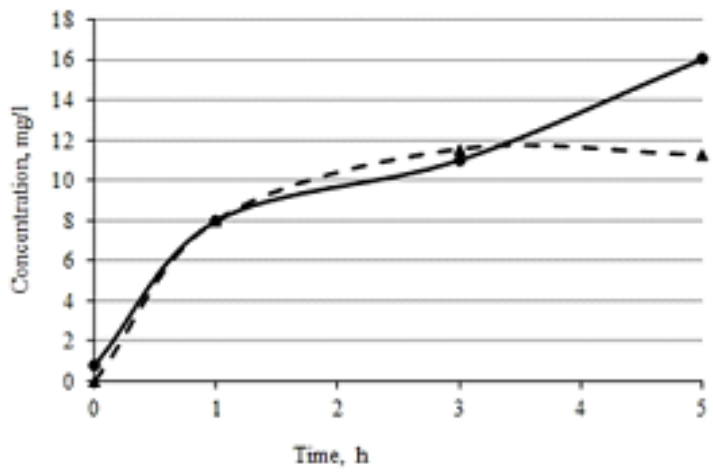

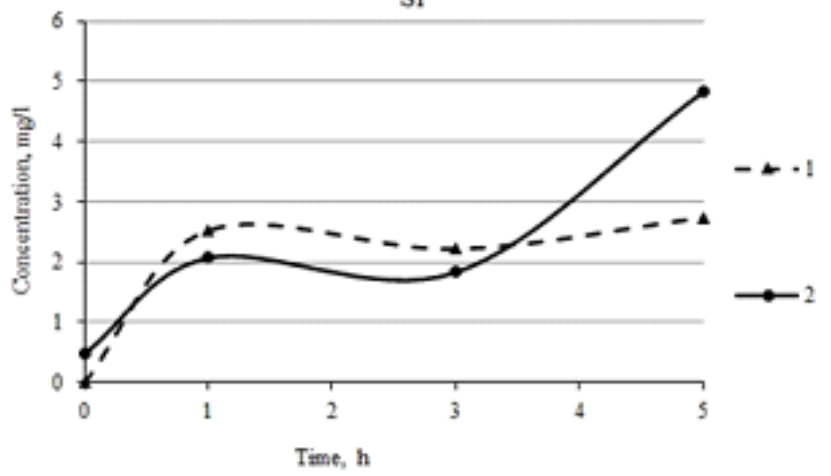

$\mathrm{K}$

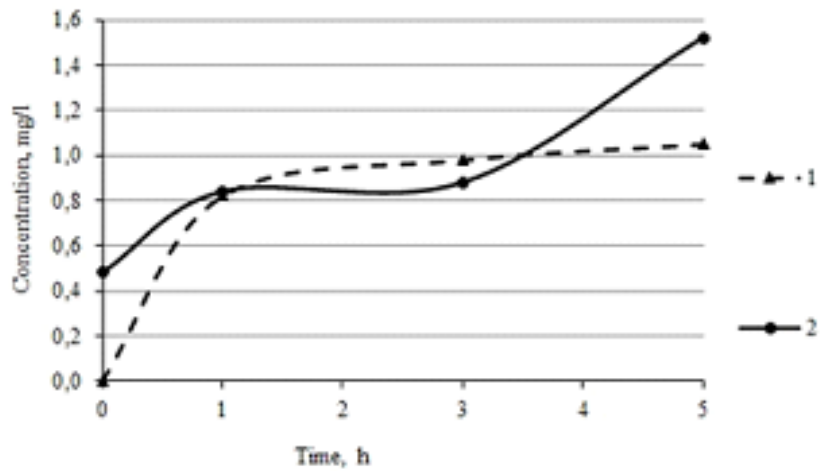

Fig. 4. Concentrations of aluminum, silicon, sodium, and potassium in the resulting solutions when interacting with water (1) and soil extract (2).

tailings of loparite ores with a weak solution of sulfuric acid leads to an intensification of the transition of metals, in particular HMs and REEs, into a soluble, and therefore bioavailable, form.

\subsection{Interaction between the dust particles of loparite ore concentration tailings and soil water}

The breakup intensity of the mineral matrix of the tailings material was also assessed by the change in the concentrations of aluminum, silicon, sodium, and potassium in the resulting solutions (Fig. 4).

For aluminum and silicon, which are part of nepheline and feldspars, an increase in concentrations in the studied solutions is characteristic: this is more characteristic of silicon, to a lesser extent of aluminum. When aluminosilicates are decomposed by hydrolysis, aluminum can form complex salts with humic and fulvic acids by entering the anionic part of the molecule [16]. An increase in acidity when replacing distilled water with a water soil extract accelerates leaching and leads to a higher concentration of alkaline and alkaline earth elements in the solution [17].

The nature of changes in the concentrations of sodium and potassium (Fig. 4) indicates that the dissolution of minerals occurs unevenly with a predominant transition into sodium solution. At the same time, the addition of dissolved organic matter (water extract of the conventionally undisturbed soil) naturally intensifies this process.
Figure 5 shows the change in the concentrations of HMs and REEs in the solution depending on the interaction time and the presence of dissolved organic matter.

As one can see, the concentrations of copper, zinc, and manganese in the resulting solutions after five hours of interaction are many times higher than the applicable fishery MPC (0.001, 0.01 and $0.01 \mathrm{mg} / 1$, respectively). A more intense transition of HMs into soluble forms was observed in the soil water extract.

Adding organic matter leads to an increase in the intensity of dissolution of the REE minerals. The process intensifies for lanthanum, cerium, neodymium. It is known that after entering the soil, REEs can be adsorbed, since organic matter is a source of negatively charged particles in weathered soils [18]. However, the long-term stability of the bond between REEs and humic substances varies, and exposure to dissolved organic matter may initiate the reverse process of desorption [19]. The REE concentration in the soil solution is directly correlated with the content of dissolved organic carbon and inversely with the soil $\mathrm{pH}[20,21]$. In general, the behavior of REEs in soils is similar to that of heavy metals [22]. No MPCs in water bodies and soils exist for these elements, and the effect of REEs on biota has not been sufficiently studied.

It is known that the concentration of light REEs in the roots of vascular plants is usually higher than in other plant organs, including shoots [23-27]. However, the accumulation of these in leaves and stems, being the 


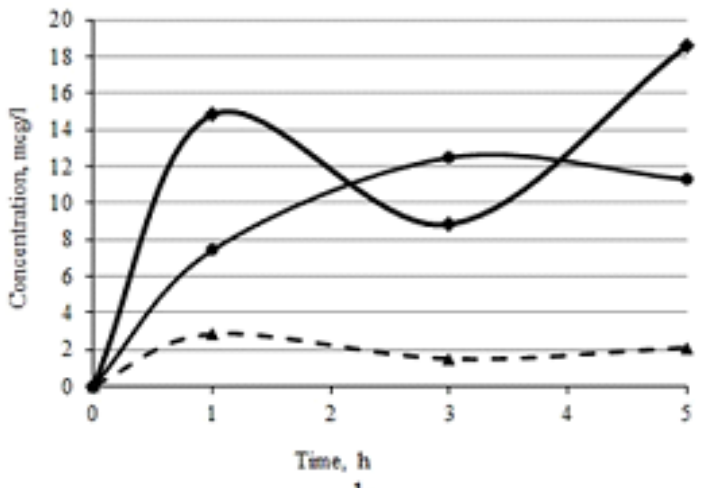

1

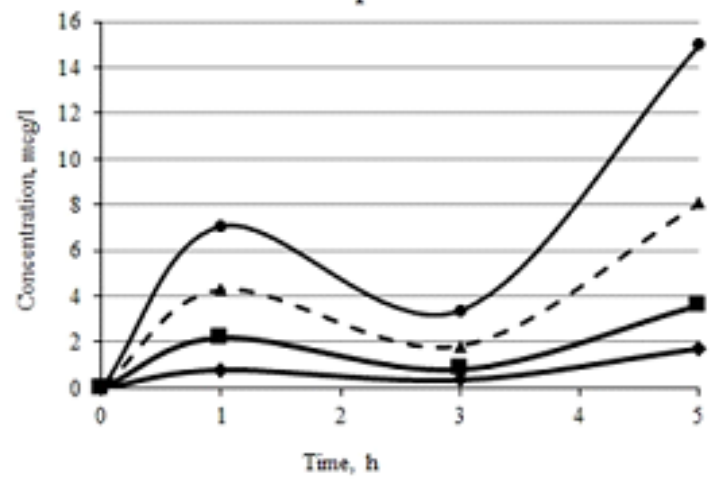

$\mathrm{HM}$

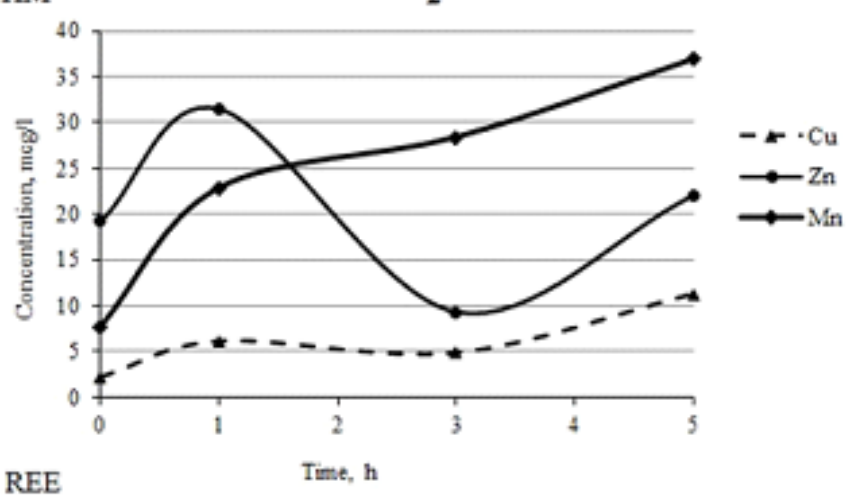

REE

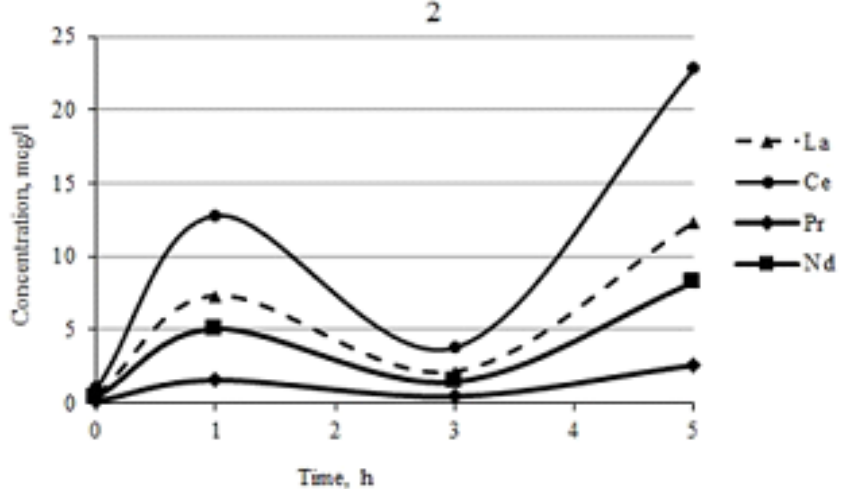

Fig. 5. Concentrations of HMs and REEs in the resulting solutions when interacting with water (1) and soil extract (2).

main organs of photosynthesis, can have major consequences for plant development [27].

We note that the strong mobilization capacity of the organic acids in the soil water extract in relation to microelements was previously reported for zinc, copper, manganese, thorium, vanadium, lanthanum, niobium, etc. [28].

\section{Conclusions}

The findings of our study on the transformation of fresh concentration tailings of loparite ore when exposed to atmospheric precipitation and modeling of leaching of mineral particles into the soil indicate the potential environmental hazard of concentration tailings dusting due to the intensified mobilization of environmentally hazardous elements (aluminum, heavy and rare earth metals).

The results of the filtrate analysis showed a manifold increase in the chemical weathering rate when exposed to acid rain. The breakup intensity of the silicate matrix of the main minerals in the tailings and the transition of environmentally hazardous elements into soluble forms in a weakly acidic environment increase materially. HM concentrations in the resulting solutions after 60 days of the experiment, when the tailings material was moistened with a dilute solution of sulfuric acid, many times exceeded the maximum permissible values for fishery water bodies. In particular, the applicable MPC for strontium was exceeded by a factor of 5 , zinc 17 , manganese 448 .
An intense transition to the solution of light REEs was observed. In particular, the concentration of lanthanum and cerium in the resulting solutions at the end of the experiment exceeds the corresponding values in the control (moistening with distilled water) by a factor of 45 and 60 , respectively. In general, the behavior of REEs during leaching is similar to that of HMs. However, unlike that of HMs, the phytotoxicity of REEs has not yet been sufficiently studied.

The concentrations of the above elements in solutions after five hours of interaction between the dust particles of the tailings with soil water greatly exceeded the fishery MPCs: for aluminum be a factor of 15 , zinc 2.1, copper 12 , manganese 3.6 .

The observed increase in the transition of HMs and REEs into solution upon the addition of organic matter is apparently associated with the intense breakup of the mineral matrix by the humic substance. The combination of the presence of water-soluble organic soil substances in solution with an increase in temperature naturally leads to a higher intensity of the transition of cations into solution, which, in addition to the main cations of rockforming minerals, include heavy metals and rare earth elements.

The migration of HMs and REEs in dissolved form is largely controlled not by the presence of free cations in solution, but by the formation of complex organic and inorganic compounds. The transition of metals into a labile form upon interaction with soil organic matter can lead to the accumulation thereof in the most toxic form for biota in the top organogenic soil horizon. 
The authors acknowledge the contribution by A.V. Timokhin and A.A. Goryachev in the form of collecting the samples and by the analysis team at the Shared Use Center, Institute of Industrial Ecology of the North, Kola Research Center at the Russian Academy of Sciences. This study was carried out as part of the research project 0226-2019-0011 and partially funded by the RFBR grant 19-05-50065 Microcosm.

\section{References}

1. M.C. Moncur, C.J. Ptacek, M. Hayashi, D.W. Blowes, S.J. Birks, Seasonal cycling and massloading of dissolved metals and sulfate discharging from an abandoned mine site in northern Canada, Applied Geochemistry, 41, 176188 (2014)

2. M.B.J. Lindsay, M.C. Moncur, J.G. Bain, J.L. Jambor, C.J. Ptacek, D.W. Blowes, Geochemical and mineralogical aspects of sulfide mine tailings, Applied Geochemistry, 57, 157-177 (2015)

3. L. Askaer, L.B. Schmidt, B. Elberling, G. Asmund, I.S. Jónsdóttir, Environmental impact on an Arctic soil-plant system resulting from metals released from coal mine waste in Svalbard $\left(78^{\circ} \mathrm{N}\right)$, Water, Air, \& Soil Pollution, 195, 99114 (2008)

4. N.M. Volkova, Influence of the mining and metallurgical region on the example of the Murmansk region of the Northwestern Federal District, Geology and mineral resources of the European North-East of Russia, Materials of the XVII Geological Congress of the Komi Republic, Syktyvkar: Institute of Geology of the Komi Scientific Center of the Ural Branch of the Russian Academy of Sciences, 297-299 (2019)

5. D.O. Dushkova, A.V. Evseev, Analysis of technogenic impact on the geosystems of the European North of Russia, Arctic and North, 4, 162-195 (2011)

6. T.I. Markovich, Features of hypergene transformation of minerals in sulfide dumps, Mineralogy of technogenesis, 2, 62-76 (2011)

7. F.Ya. Rovinsky (ed.), Acid precipitation. LongTerm Trends (L.: Gidrometeoizdat, 1990)

8. B.S. Smolyakov, L.A. Pavlyuk, A.M. Nemirovsky, Acidity and ionic composition of atmospheric precipitation and aerosols in the Novosibirsk region, Optics of the atmosphere and ocean, 9 (6), 773-779 (1996)

9. A.A. Goryachev, E.A. Krasavtseva, V.V. Laschuk, P.V. Ikkonen, A.A. Smirnov, V.V. Maksimova, D.V. Makarov, Assessment of the environmental hazard and the possibility of processing the tailings of the dressing of loparite ores, Ecology and Industry of Russia, 24 (12), 46$51(2020)$

10. A.A. Goryachev, V.V. Laschuk, E.A. Krasavtseva, N.L. Alfertyev, D.V. Makarov, Geoecological assessment of the current state of tailing dumps of different ages at the Karnasurt mine, Proceedings of Fersman scientific session of the State Institute of the KSC RAS, 17, 128132 (2020)

11. V.V. Maksimova, E.A. Krasavtseva, D.V. Makarov, V.A. Masloboev, Modeling of chemical weathering of apatite-nepheline ore dressing tailings under the influence of atmospheric precipitation, Mineralogy of technogenesis, 14, 203-209 (2013)

12. I.V. Volkov, Reactions of microelements with humic acids as the basis for sorption decontamination and treatment of industrial waste (Yekaterinburg, Institute of Solid State Chemistry, Ural Branch of the Russian Academy of Sciences, 2016)

13. K. Mostofa, T. Yoshioka, A. Mottaleb, D. Vione, Complexation of Dissolved Organic Matter with Trace Metal Ions in Natural Waters, Photobiogeochemistry of Organic Matter, Environmental Science and Engineering (Environmental Engineering), Springer (2013)

14. GOST 26423-85, Soils, Methods for determining the specific electrical conductivity, $\mathrm{pH}$ and solid residue of the aqueous extract, (Moscow, Standartinform, 2011)

15. V.V. Nikonov, N.V. Lukina, V.S. Bezel, et all, Trace elements in boreal forests (Moscow, Nauka, 2004)

16. D. Orlov, Humic substances in the biosphere, Soil Science, 8, 1019-1022 (2003)

17. A. Savenko, V. Savenko, A. Dubinin, Leaching of trace elements from rocks under the action of organic acids, Moscow University Bulletin, Series 4, Geology, 6, 70-76 (2017)

18. R. Beckwith, J. Butler, Aspect Of The Chemistry Of Soil Organic Matter, Soil, An Australian Viewpoint, Vic CSIRO/Academic Press (1993)

19. W. Xiangke, D. Wenming, D. Xiongxin, W. Aixia, D. Jinzhou, T. Zuyi, Sorption and desorption of $\mathrm{Eu}$ and $\mathrm{Yb}$ on alumina: mechanisms and effect of fulvic acid, Applied Radiation and Isotopes, 52 (2), 165-173 (2000)

20. O. Pourret, M. Davranche, G. Gruau, A. Dia, Organic complexation of rare earth elements in natural waters: Evaluating model calculations from ultrafiltration data, Geochimica et Cosmochimica Acta, 71 (11), 2718-2735 (2007)

21. J. Tang, K. Johannesson, Rare earth elements adsorption onto Carrizo sand: Influence of strong solution complexation, Chemical Geology, 279 (3-4), 120-133 (2010)

22. S. Ramos, G. Dinali, C. Oliveira, G. Martins, C. Moreira, J. Siqueira, L. Guilherme, Rare Earth Elements in the Soil Environment, Current Pollution Reports, 2 (1), 28-50 (2016)

23. D. Carpenter, C. Boutin, J.E. Allison, J.L. Parsons, D.M. Ellis, Uptake and Effects of Six 
Rare Earth Elements (REEs) on Selected Native and Crop Species Growing in Contaminated Soils, PloS one, 10 (6), e0129936 (2015)

24. N. Grosjean, M. Le Jean, C. Berthelot, et all, Accumulation and fractionation of rare earth elements are conserved traits in the Phytolacca genus, Sci. Rep., 9, 18458 (2019)

25. P. Mikołajczak, K. Borowiak, P. Niedzielski, Phytoextraction of rare earth elements in herbaceous plant species growing close to roads, Environmental Science and Pollution Research, 24 (16), 14091-14103 (2017)

26. M. Nazreen, A. Amalina, M. Omar, Bioaccumulation of Rare Earth Element by Water Lettuce (Pistia stratiotes), Oriental Journal of Chemistry, 33, 1097-1102 (2017)

27. P. Thomas, D. Carpenter, C. Boutin, J. Allison, Rare earth elements (REEs): Effects on germination and growth of selected crop and native plant species, Chemosphere, 96, 57-66 (2013)

28. E.M. Hausrath, A. Neaman, S.L. Brantley, Elemental release from dissolving basalt and granite with and without organic ligands, Amer. J. Sci., 309, 633-660 (2009). 